\title{
Evaluation of Root Extract of Cyphostemma Adenocaule (Vitaceae) for Antioxidant Activity, Brine Shrimp Toxicity, and Antiproliferative Activity against Hela Cervical Cancer Cells
}

\author{
Daniel Zacharia Matata ${ }^{1 *}$, Francis Machumi1, Olipa David Ngassapa ${ }^{2}$, Mainen Julius Moshi ${ }^{3}$, \\ Fidelice M.S. Mafumiko ${ }^{4}$, Kenneth Oosthuizen ${ }^{5}$,Bresler Swanepoel ${ }^{5}$, Luanne Venables ${ }^{5}$, Trevor \\ Craig Koekemoer ${ }^{5}$, Paul Erasto Kazyoba ${ }^{6}$, Maryna van de Venter \\ ${ }^{1}$ Department of Natural Products Development and Formulations Muhimbili University of Health and Allied \\ Sciences, P. O. Box 65001, Dar es Salaam, Tanzania \\ ${ }^{2}$ Department of Pharmacognosy, School of Pharmacy, Muhimbili University of Health and Allied Sciences, $P$. \\ O. Box 65013, Dar es Salaam, Tanzania \\ ${ }^{3}$ Department of Biological and Preclinical Studies, Muhimbili University of Health and Allied Sciences, P. O. \\ Box 65001, Dar es Salaam, Tanzania \\ ${ }^{4}$ Government Chemist Laboratory Authority, P.O. Box 164, Dar es Salaam, Tanzania \\ ${ }^{5}$ Department of Biochemistry and Microbiology, P.O. Box 77000, Nelson Mandela University, Port Elizabeth, \\ South Africa \\ ${ }^{6}$ Department of Research Coordination and Promotion, National Institute for Medical Research, P.O. Box 9653 \\ Dar es Salaam, Tanzania
}

\begin{abstract}
*Corresponding Author: Daniel Zacharia Matata, Department of Natural Products Development and Formulations Muhimbili University of Health and Allied Sciences, P. O. Box 65001, Dar es Salaam, Tanzania
\end{abstract}

Abstract: Cyphostemma adenocaule (Vitaceae) is used by traditional health practitioners in northeastern Tanzania, for treatment of cancer but there is no information available regarding its safety and efficacy.

This study was conducted to determine the activity of the root extracts against brine shrimps, antioxidant and cytotoxicity against HeLa cancer cells.

A (1:1) dichloromethanel methanol extract of powdered roots was fractionated by vacuum liquid chromatography to obtain petroleum ether, dichloromethane and ethyl acetate fractions, which were tested for toxicity against Artemia salina larvae and antioxidant activity using the DPPH and FRAP assays.

The ethyl acetate fraction exhibited the highest toxicity on brine shrimps $\left(L C_{50}=3.9 \mu \mathrm{g} / \mathrm{ml}\right)$, and antioxidant activity with EC50 $=162.88 \mu \mathrm{g} / \mathrm{ml}$ and $100.04 \mathrm{Fe}^{2+} \mu M$ ECGC equivalent/g dry weight, for DPPH \& FRAP assay respectively.

Further tests of fraction to the HeLa cervical cancer cells, demonstrated apoptotic cell death with the (IC 50 $3.4 \pm 0.3 \mu \mathrm{g} / \mathrm{ml})$, that was characterized by cell cycle arrest at the $M$ phase, phosphatidylserine externalization, Caspase 3 and 8 activation and time-dependent reduction in mitochondrial membrane potential down to zero after $48 \mathrm{~h}$.

The results support claims by THPs, however, more studies using different cancer cell lines, are needed to determine clinical application of the results.

Keywords: Antioxidant, Antiproliferative, Brine shrimp toxicity, Cyphostemma adenocaule, Hela cervical cancer cells

\section{IMPORTANT ABBREVIATIONS AND ACRONYMS}

DW Dry weight

VLC Vaccum Liquid Chromatography

BST Brine Shrimps Lethality Test

FRAP Ferric Reducing Antioxidant Potential 


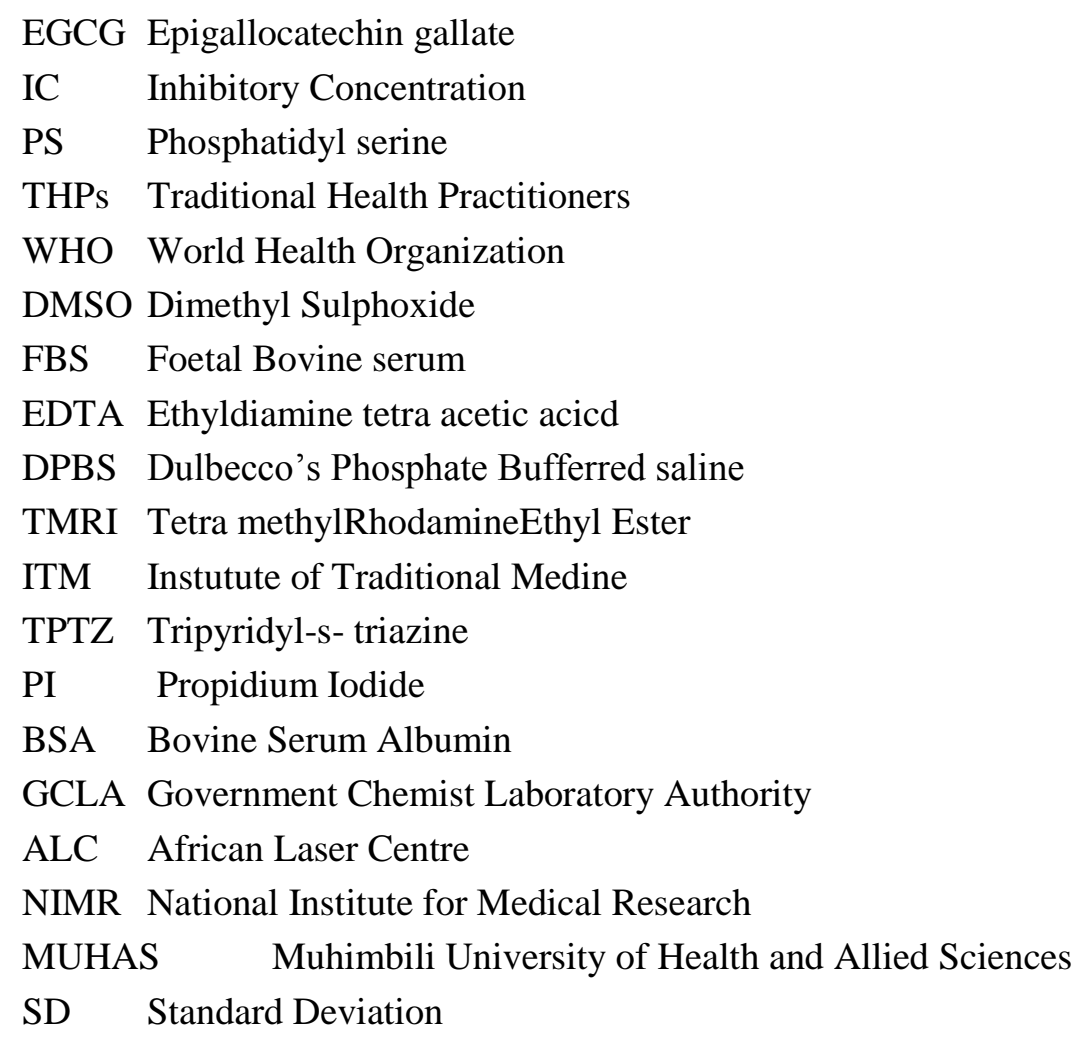

\section{INTRODUCTION}

According to the World Cancer Report of WHO (2020) there were an estimated 18.1 million new cases and 9.6 million deaths from cancer in 2018 and prevalence is estimated to increase to 29.4 million by the year 2040 [1]. Most cancers show no symptoms until the disease is diagnosed, often when it has already reached progressive stages [2]. Late diagnosis of cancer is a common phenomenon in developing countries, largely because in most of these countries there are, either none or few, specialized cancer treatment facilities. Until recently, Tanzania had only the Ocean Road Cancer Institute, situated in Dar es Salaam. Therefore, most cancer patients depend on Traditional Health Practitioners (THPs) as their first point of care, where some are claimed to be cured by the traditional medicines, while others are not and end up getting specialized care when it is already too late. Cyphostemma adenocaule is one of plants that is claimed by traditional health practitioners in Kilimanjaro region to cure some cancers.

Cyphostemma adenocaule (Steud. ex A. Rich.) Desc.ex Wild. \& R.B. Drumm is a shrub-like climber belonging to the family Vitaceae. It is distributed in East and Central parts of the African continent, south of Sahara desert [3]. The plant is traditionally used for medicinal purposes in different parts of Africa. In Ethiopia the root powder is used for treatment of skull wounds and snake bites [4]. It is used for various illnesses including malaria, helminthic infection, cancer, tumours, snake bite, rabies, and anthrax [5]. In West Africa leaves are used as wild vegetable [3], while in Samburu-Kenya and parts of Ethiopia, the plant is used for treatment of cancer[6,7]. An infusion of fresh leaves is used as a purgative and is also reported to have anti-inflammatory activity [8]. It is also used to treat swollen abdomen and pneumonia, while the dried entire plant is used for wound healing [8].

The aim of this study was to evaluate extracts of Cyphostemma adenocaule for antiproliferative, antioxidant and brine shrimp toxicity, as part of initial evaluation of the plant for efficacy.

\section{Materials AND Methods}

\subsection{Materials}

Sea salt was prepared from water collected from the Indian Ocean along the coast of Dar es Salaam, Tanzania, and dried by boiling to obtain sea salt. Brine shrimp eggs were obtained from Aquaculture Innovations (Grahamstown, South Africa). Dimethyl sulphoxide (DMSO) was purchased from Sigma (Poole, Dorset, UK). Ethanol, dichloromethane, petroleum ether and ethyl acetate were purchased from CARLO ERBA (Van de Reut, France). HeLa cervical cancer cells were purchased from Cellonex (South Africa). RPMI 1640 cell culture medium and foetal bovine serum (FBS) were 
purchased from GE Healthcare Life Sciences (Logan, UT, USA). Trypsin-EDTA, Dulbecco's phosphate buffered saline (DPBS) with and without $\mathrm{Ca}^{2+}$ and $\mathrm{Mg}^{2+}$ were purchased from Lonza (Wakersville, MA, USA). Trypan blue, bis benzamide H 33342 (Hoechst 33342), melphalan, penicillin/streptomycin and bovine serum albumin fraction V were purchased from Sigma-Aldrich (St. Louis, MI, USA). Tetramethyl rhodamine ethyl ester (TMRE) was purchased from Molecular Probes - Life Technologies - Thermo Fisher Scientific (Logan, UT, USA). Annexin V-FITC/PI kit was purchased from MACS Miltenyi Biotec (Cologne, Germany). Cleaved caspase 3 (Asp175), rabbit mAb, cleaved caspase 8 (Asp 391), and Anti-rabbit IgG (H+L), F(ab')2 fragment (Alexa fluor ${ }^{\circledR} 647$ conjugate was purchased from Cell Signaling Technology (Danvers, MA, USA).

\subsection{Methods}

\subsubsection{Collection and extraction of plant material}

Cyphostemma adenocaule roots were collected in Same District, Kilimanjaro region, in August 2015. Identification and collection of plant material was done by Mr Selemani Omari Haji, a Botanist at the Department of Botany, University of Dar es Salaam, and a voucher specimen (voucher specimen No. DZM 33) is deposited in the Herbarium of the Institute of Traditional Medicine (ITM), Muhimbili University of Health and Allied Sciences and duplicates are deposited in the Herbarium of the Department of Botany, University of Dar es Salaam. On arrival at the ITM, the roots were cleaned, dried and then ground by means of a milling machine. The powder $(500 \mathrm{~g})$ was macerated with methanol: dichloromethane (1:1) mixture for $24 \mathrm{~h}$. The resulting extract was decanted, followed by filtration and the solvent removed using a rotary evaporator (Heidolph Instruments GmbH, Walpersdorfer - Germany) at $40^{\circ} \mathrm{C}$, under reduced pressure. Extracts were freeze-dried (Edwards, BOC Ltd. Crawley Sussex- England) to remove any traces of water. Dried extracts were stored in vials, in a freezer at $-20^{\circ} \mathrm{C}$, until when needed for experiments.

\subsubsection{Vacuum liquid chromatography}

Crude extracts were homogenised in a (1:1) ratio with silica gel (60 - 120 mesh) and then fractionated using solvents of varying polarities, starting with petroleum ether, followed by ethyl acetate and methanol. Solvents were removed from the collected extract fractions by a rotary evaporator, and remaining traces of water were removed by freeze drying. The recoveries from each solvent were; $1.47 \mathrm{~g}$ (petroleum ether), $33.02 \mathrm{~g}$ (ethyl acetate) and $7.65 \mathrm{~g}$ (methanol). Recovered fraction residues, after freeze drying, were kept in a freezer, at $-20^{\circ} \mathrm{C}$, until they were needed for experiments.

\subsubsection{Brine shrimp lethality test (BST)}

The brine shrimp lethality experiments were conducted as described by Meyer et al., 1982 [9], with modifications [10]. Ten Artemia salina larvae were incubated in duplicate vials of extracts, while control larvae were incubated in a pair of vials which contained 0.6\% DMSO in seawater only. After $24 \mathrm{~h}$ the percentage of dead nauplii was determined and the Fig P computer program (Biosoft Inc., USA) was used to plot the graph of logarithm of concentrations against the mean percentage mortality. Regression equations were used to compute concentrations that killed $50 \%$ of the larvae and their $95 \%$ confidence intervals [11]

\subsubsection{Testing for antioxidant activity}

\subsubsection{Ferric reducing antioxidant potential (FRAP) assay}

A modified version of the Benzie and Strain (1996) assay for the determination of the ferric reducing antioxidant potential of $C$. adenocaule extracts was used(12). Briefly, $50 \mu l$ of extract at concentrations of $25,50,100$ and $200 \mu \mathrm{g} / \mathrm{ml}$ were added to the wells of a 96-well microtiter plate, followed by addition of $200 \mu \mathrm{l}$ of FRAP reagent $(10: 1: 1 \mathrm{v} / \mathrm{v} / \mathrm{v}$ of $300 \mathrm{mM}$ acetate buffer at $\mathrm{pH} 3.6,10$ $\mathrm{mM}$ tripyridyl-s-triazine (TPTZ) in $40 \mathrm{mM} \mathrm{HCl}$ and $20 \mathrm{mM} \mathrm{FeCl}_{3}$ ). The reagents were incubated for $30 \mathrm{~min}$, at room temperature, after which absorbances were measured at $593 \mathrm{~nm}$ using a Biotek ${ }^{\circledR}$ Power Wave XS microtiter plate reader (Winooski, VT, USA). Epigallocatechin gallate (EGCG), 10 $\mathrm{mM}$, was used as the positive control for the assay. Analyses were performed in four replicates for each concentration and results are presented as the mean of four observations with standard deviations and expressed as $\mu \mathrm{mol}$ (ferrous sulphate) EGCG equivalent/g dry weight.

\subsubsection{DPPH radical scavenging assay}

DPPH radical scavenging activity of $C$. adenocaule extracts was determined using a method described by Sandya Kumar et al., 2012 for measurement of scavenging capacity of antioxidants with 


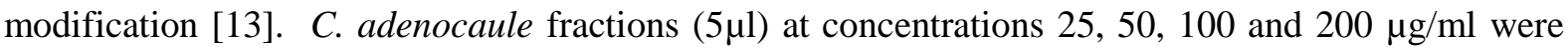
added to 96 -well microtitre plates followed by $120 \mu \mathrm{l}$ of Tris-HCl buffer $(50 \mathrm{mM}, \mathrm{pH} 7.4)$ and $120 \mu \mathrm{l}$ of DPPH $(0.1 \mathrm{mM}) ; 10 \mathrm{mM}$ epigallocatechin gallate (EGCG) served as the positive control. The plates were incubated for $20 \mathrm{~min}$ at room temperature and absorbance measured at $513 \mathrm{~nm}$ using a Biotek® Power Wave XS microtiter plate reader (Winooski, VT, USA). Antioxidant activity was calculated as \% DPPH radical scavenging activity, by substituting the absorbance values into the following equation:

$$
\% \text { DPPH Radical Scavenging Activity }=\frac{((\text { Abs.Control-Abs.Extract }))}{\text { Abs.Control }}
$$

The results are reported as percentage of DPPH scavenged relative to the control.

\subsubsection{Antiproliferative activity}

The extract fractions were tested for antiproliferative activity against HeLa cervical cancer cells as described in our previous publication [14], using cells which were routinely maintained in antibiotic free RPMI 1640 culture medium supplemented with $10 \%$ fetal bovine serum (FBS) at $37^{\circ} \mathrm{C}$ with $5 \%$ $\mathrm{CO}_{2}$. Melphalan $(10 \mu \mathrm{M})$ served as the positive control for all subsequent experiments. Incubation with the extracts was done as described in our earlier publication [14].

\subsubsection{Cytotoxicity}

HeLa cervical cancer cells were placed into a 96-well plate at 4000 cells per well and left overnight to attach. Cells were treated with the ethyl acetate extract at concentrations ranging from $0.1-200$ $\mu \mathrm{g} / \mathrm{ml}$ for $48 \mathrm{~h}$ at $37^{\circ} \mathrm{C}$ with $5 \% \mathrm{CO}_{2}$. Treatment medium was removed and replaced with a $5 \mu \mathrm{g} / \mathrm{ml}$ solution of Hoechst 33342 in Dulbecco's phosphate-buffered saline (DPBS) with $\mathrm{Ca}^{2+}$ and $\mathrm{Mg}^{2+}$ and incubated for $20 \mathrm{~min}$ at $37^{\circ} \mathrm{C}$. Prior to image acquisition, $10 \mu \mathrm{g} / \mathrm{ml}$ of propidium iodide (PI) was added. Images were acquired using the DAPI and Texas Red filter sets for Hoechst 33342 and PI, respectively.

\subsubsection{Cell cycle analysis}

Cells were seeded as for cytotoxicity determination, then incubated with test sample at its $\mathrm{IC}_{50}$ for 24 and $48 \mathrm{~h}$ at $37^{\circ} \mathrm{C}$. The medium was removed prior to the addition of $50 \mu \mathrm{l}$ aliquots of a mixture of Annexin V-FITC (20 $\mu \mathrm{l}$ of manufacturers stock) and Hoechst $33342(5 \mu \mathrm{g} / \mathrm{ml})$ in $2 \mathrm{ml}$ Dulbelcco's Phosphate Buffered Saline (DPBS) with $\mathrm{Ca}^{2+}$ and $\mathrm{Mg}^{2+}$. The cells were incubated at $25^{\circ} \mathrm{C}-30^{\circ} \mathrm{C}$ for 15 min after which they were imaged using the DAPI and FITC filter sets for the Hoechst 33342 and Annexin V-FITC, respectively.

\subsubsection{Image acquisition and analysis}

The Image Xpress Micro XLS Wide field High-Content Analysis System (Molecular Devices ${ }^{\circ}$, San Jose, CA, USA) together with the Meta Xpress ${ }^{\circ}$ High-Content Image Acquisition and Analysis Software were used to acquire and analyse all images, for antiproliferative related experiments. Image acquisition of 9 sites per well, of a 96-well plate, was done using a 10x Plan Fluor objective

\subsubsection{Phosphatidylserine translocation}

Cells were seeded, treated and stained as for cell cycle analysis [14] with the exception that PI (10 $\mu \mathrm{g} / \mathrm{ml}$ ) was also added prior to image acquisition. The DAPI, FITC and Texas Red filter sets were used for the Hoechst 33342, Annexin V-FITC and PI, respectively.

\subsubsection{Mitochondrial membrane potential}

Seeded cells were treated as for cell cycle analysis [14]. The treatment medium was replaced with $100 \mu \mathrm{l}$ aliquots of a mixture of $0.05 \mathrm{mM}$ Tetramethyl rhodamine, ethyl ester (TMRE) and $5 \mu \mathrm{g} / \mathrm{ml}$ Hoechst 33342 in DPBS with $\mathrm{Ca}^{2+}$ and $\mathrm{Mg}^{2+}$. Cells were incubated for $30 \mathrm{~min}$ at $37^{\circ} \mathrm{C}$ prior to image acquisition. The DAPI and TRITC filter sets were applied for the Hoechst 33342 and TMRE, respectively.

\subsubsection{Caspase 3 and 8 activation}

Cells were prepared as for cell cycle analysis and aspirated for antibody staining. Washing was done using DPBS containing $\mathrm{Ca}^{2+}$ and $\mathrm{Mg}^{2+}$ and fixed by $4 \%$ paraformaldehyde followed by incubation at room temperature for $15 \mathrm{~min}$. Excess paraformaldehyde was removed through washing with DPBS prior to permeabilization with $80 \%$ ice cold methanol for $10 \mathrm{~min}$ at $-20^{\circ} \mathrm{C}$. Cells were again washed with DPBS and then blocked for $30 \mathrm{~min}$ at room temperature using $0.5 \%$ bovine serum albumin 
(BSA) in DPBS. Rabbit anti-caspase 3 or 8 monoclonal antibody was added to the cells at the ratio of (1:50) and incubated for $1 \mathrm{~h}$ at $37^{\circ} \mathrm{C}$. Cells were washed with DPBS to remove excess antibody prior to the addition of the Alexa 647-conjugated goat anti-rabbit secondary antibody. After incubation at $37^{\circ} \mathrm{C}$ for 30 -min the cells were washed and $100 \mu \mathrm{l}$ of Hoechst $33342(5 \mu \mathrm{g} / \mathrm{ml})$ in DPBS added as a counterstain. The DAPI and Cy5 filter sets were used for the Hoechst 33342 and Alexa 647conjugated goat anti-rabbit secondary antibody, respectively.

\subsubsection{Statistical analysis}

All experiments were conducted at least three times with three different transfer numbers. The data were analysed using the Graph Pad Prism software version 5.01, which plots percentage cell death against logarithm of concentrations. Statistical analysis was performed by means of the student $t$-test for two samples assuming equal variance. Error bars represent the standard deviation of the mean $(\mathrm{SD}, \mathrm{n}=3)$.

\section{RESUlTS}

\subsection{Brine Shrimp Assay}

Toxicity of petroleum ether, ethyl acetate and methanol fractions to brine shrimps, following an exposure of $24 \mathrm{~h}$ are presented in Table1 with the respective $95 \%$ confidence intervals. The ethyl acetate fraction exhibited high brine shrimp toxicity with mean $\mathrm{LC}_{50}=3.9 \mu \mathrm{g} / \mathrm{ml} ; 95 \% \mathrm{CI}(2.3-6.7)$. This fraction exhibited higher toxicity than the positive control, cyclophosphamide $\left(\mathrm{LC}_{50}=16.1\right.$ $\mu \mathrm{g} / \mathrm{mL}$ ) which is a known anticancer drug. The methanol fraction also exhibited toxicity with $\mathrm{LC}_{50}=$ $22.1 \mu \mathrm{g} / \mathrm{ml}$, while for petroleum ether fraction the recovered amount was too small for the test.

Table 1: Brine shrimps test results of fractions of $C$. adenocaule root extract

\begin{tabular}{|l|l|l|}
\hline Sample & LC $\mathbf{5 0 \mu \mathrm { g } / \mathrm { mL }}$ & $\mathbf{9 5 \% \mathbf { C I }}$ \\
\hline Ethyl acetate Fraction & 3.908 & $2.263-6.749$ \\
\hline Methanol Fraction & 22.08 & $10.713-48.522$ \\
\hline Cyclophosphamide & 16.12 & $10.32-24.95$ \\
\hline
\end{tabular}

\subsection{Antioxidant Activity}

The $C$. adenocaule root ethyl acetate fraction exhibited dose-dependent antioxidant activity in both the FRAP and DPPH assays at concentrations of $25-200 \mu \mathrm{g} / \mathrm{ml}$ (Figure 1). The $\mathrm{EC}_{50}$ values computed from the regression lines were $100.04 \mathrm{Fe}^{2+} / \mathrm{g} \mathrm{DW}$ for FRAP and $162.88 \mu \mathrm{g} / \mathrm{ml}$ for DPPH. Both methods indicated moderate antioxidant capacity.
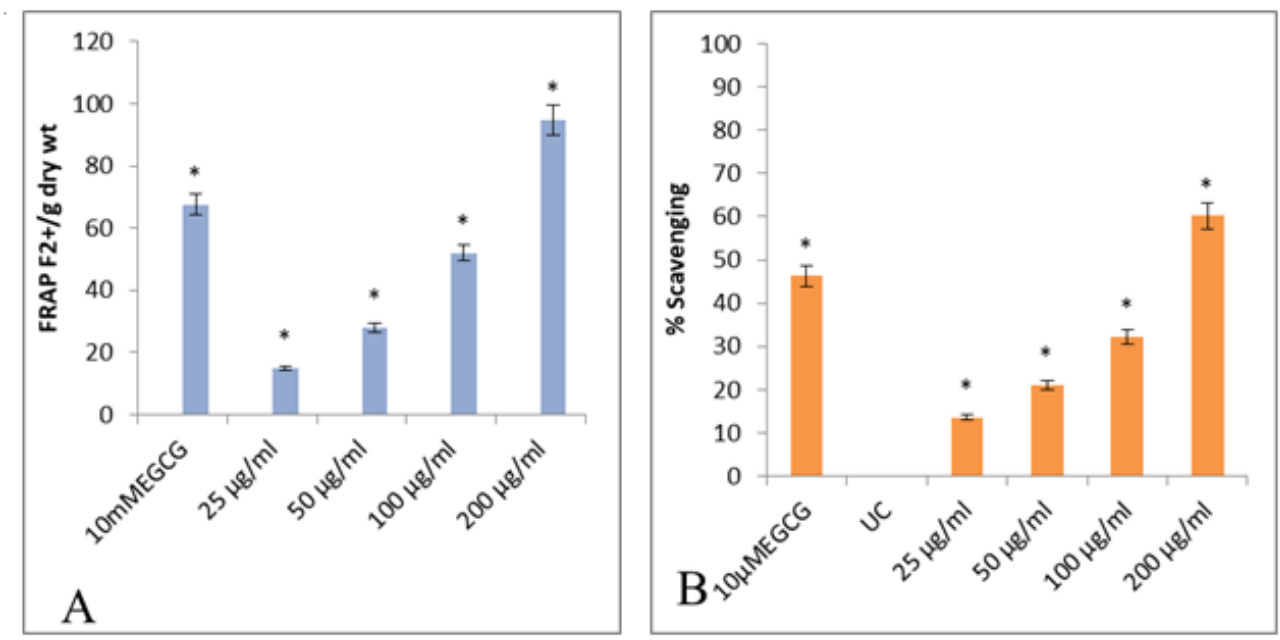

Figure 1: Antioxidant activity of ethyl acetate extracts of $C$. adenocaule (Roots) determined by FRAP (A) and $\mathrm{DPPH}$ (B). assays. Error bars represent means \pm SD for three independent experiments. * $\mathrm{P}<0.05$ relative to control. 


\subsection{Cytotoxicity To Hela Cancer Cells}

Cyphostemma adenocaule ethyl acetate fraction, at 24h, exhibited high toxicity against the Hela cervical cancer cells with an $\mathrm{IC}_{50}=3.4 \pm 0.3 \mu \mathrm{g} / \mathrm{ml}$ (Figure 2)

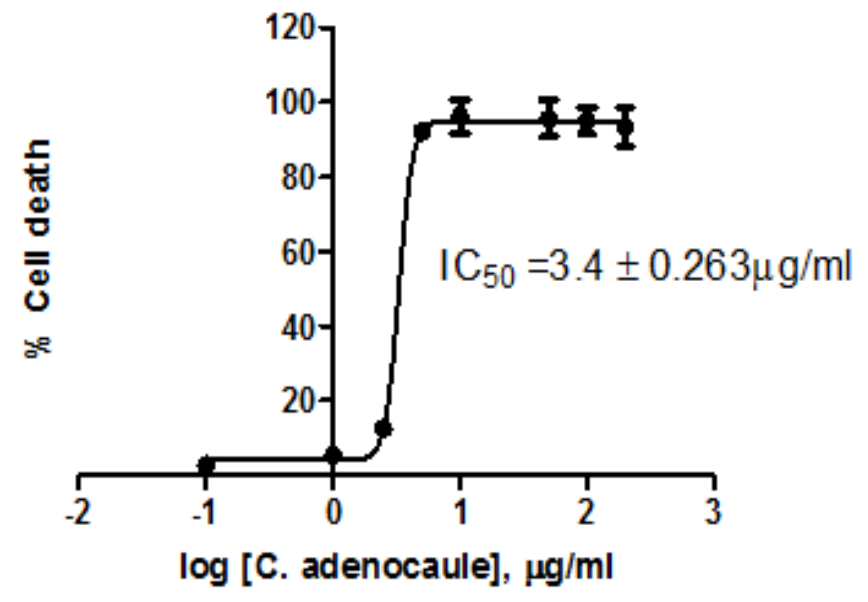

Figure 2: Cytotoxicity of $C$. adenocaule root ethyl acetate extract fraction determined by Hoechst/PI staining following a $24 \mathrm{~h}$ exposure. The results are presented as mean $\pm \operatorname{SD}(n=3)$.

\subsection{Effect on Hela Cervical Cancer Cells}

Figure 3A shows that the ethyl acetate fraction of $C$. adenocaule caused apoptosis of the HeLa cervical cancer cells, characterized by reduced number of cells re-entering the cell cycle at the Go/G1 phase, suppressed G2 and S phase and accumulation of cells at the early M phase. Consequently, there were also reduced number of cells entering the late mitosis phase.

Exposure of cells to the ethyl acetate fraction for $48 \mathrm{~h}$, caused a 3.3-fold rise in percentage apoptotic cells (staining positive with Annexin V-FITC) and arrest at early M-phase when compared to negative control. The percentage cells in early M-phase increased from $19.6 \pm 1.4 \%$ in the control to $72.8 \pm$ $10.9 \%$ in the sample, representing a 3.7-fold increase (Figure 3A).
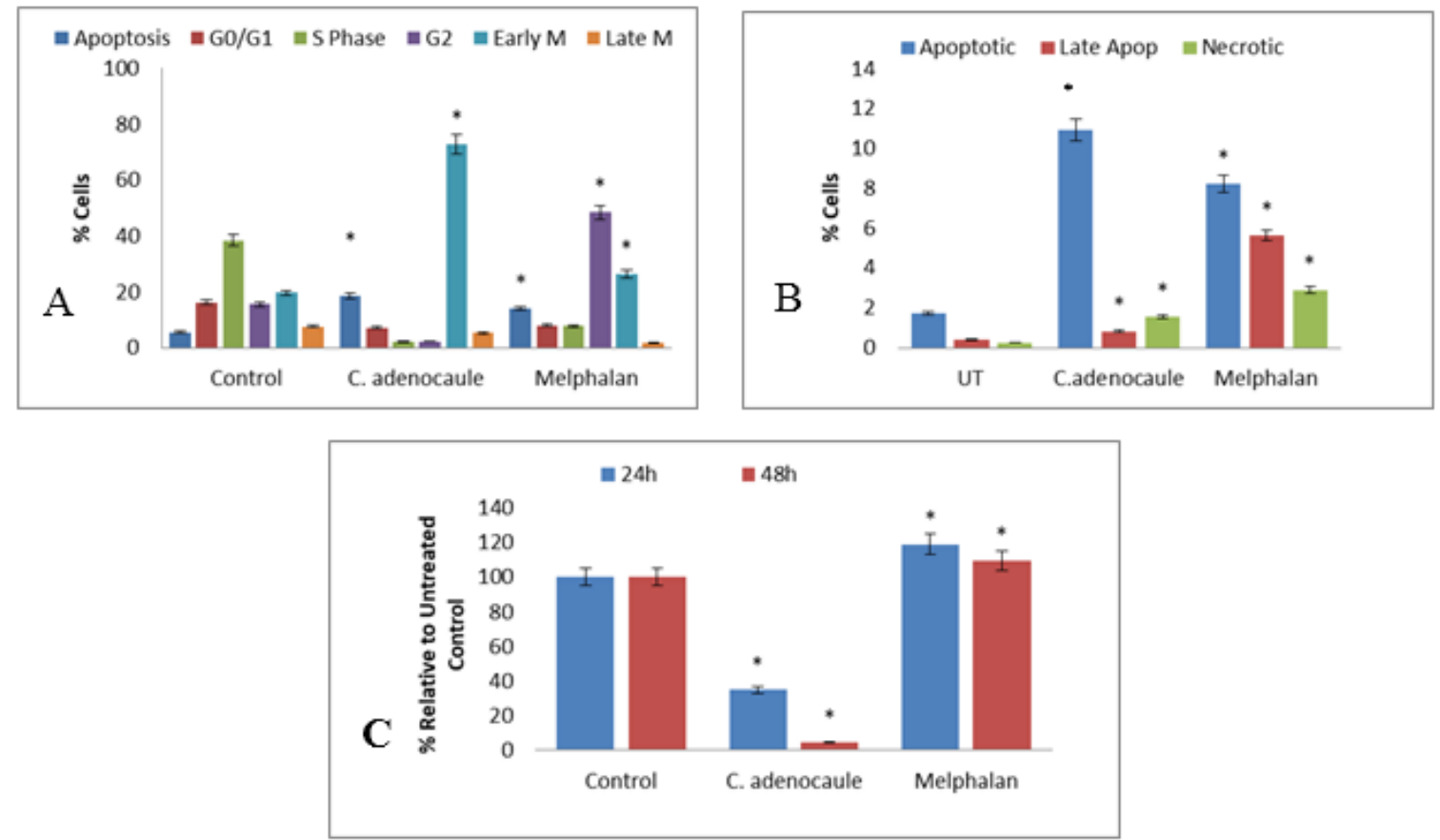

Figure3: HeLa cancer cells exposed to ethyl acetate extract of $C$. adenocaule for 24 and $48 \mathrm{~h}$. Key: $A=$ Cell cycle analysis, $\mathrm{B}=$ Phosphatidylserine translocation, $\mathrm{C}=$ Mitochondrial membrane potential (TMRE staining). The results are presented as means $\pm \mathrm{SD}\left(\mathrm{n}=4\right.$ of three individual experiments.) ${ }^{*} \mathrm{P}<0.05$ compared to untreated control (UT). 


\subsection{Phosphatidylserine (PS) Translocation}

Figure 3B shows increased number of cells showing externalization of phosphatidylserine; there was nearly $90 \%$ increase in the number showing externalization of cell membrane phosphatidylserine. Annexin V binds with high specificity to (PS) and, therefore, it is used to detect apoptotic cells after translocation of PS to the outer leaflet of the plasma membrane. Propidium iodide (PI) is used in conjunction with Annexin V because it enters necrotic cells through their compromised membranes and enables the differentiation of apoptotic and necrotic cells.

\subsection{Mitochondrial Membrane Potential}

The trimethyl rhodamine ethyl ester (TMRE) was applied to detect changes in membrane potential. Exposure of HeLa cervical cancer cells to $C$. adenocaule root ethyl acetate fraction caused a significant time-dependent reduction in membrane potential after 24 and $48 \mathrm{~h}$ exposure with almost no detectable accumulation of TMRE at 48h (Figure 3C).

\subsection{Caspase Activation}

There was no change in levels of activated caspase 3 and 8 after 24h exposure of Hela cervical cancer cells to ethyl acetate fraction when compared to untreated controls. However, after $48 \mathrm{~h}$ significant activation of both caspase 3 and 8 was observed (Figure 4). Caspase 3 increased by $13.3 \%$ and caspase 8 by $25.5 \%$ relative to untreated control.
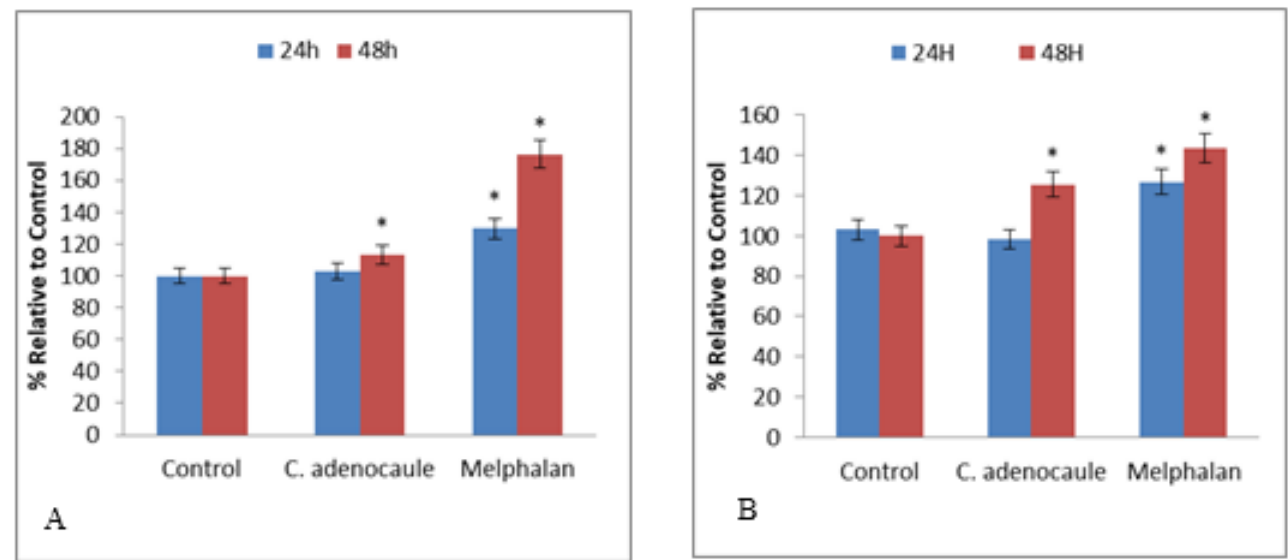

Figure 4: Caspase 3 (A) and 8 (B) activation after exposure of HeLa cancer cells to ethyl acetate root extract of $C$. adenocaule for 24 and $48 \mathrm{~h}$. The results are presented as Mean $\pm \mathrm{SD}$ $(n=4) .{ }^{*} \mathrm{P}<0.05$ compared to untreated control.

\section{DISCUSSION}

In this study it has been demonstrated that Cyphostemma adenocaule root extract has cytotoxic activity against the HeLa cervical cancer cells. Although the results are still very preliminary, it seems the highest activity resides in the intermediately polar, ethyl acetate fraction, followed by the methanol fraction. Evidence for the occurrence of apoptosis is corroborated by the externalization of membrane phosphatidylserine, which was almost 90\% after incubation of the cells with the ethyl acetate fraction for $48 \mathrm{~h}$. Similarly, the ethyl acetate and methanol fractions exhibited high and moderate toxicity, respectively, against Artemia salina nauplii, with toxicity higher than that of the standard drug cyclophosphamide, and going by similar previous observations [11], these results support the likelihood of presence of cytotoxic activity against cancer cell lines. There is high similarity between the cytotoxicity on HeLa cells results and brine shrimp lethality test results, whereby the $\mathrm{IC}_{50}$ for HeLa cells was $3.4 \mu \mathrm{g} / \mathrm{ml}$ and for brine shrimp test the $\mathrm{LC}_{50}$ was $3.9 \mu \mathrm{g} / \mathrm{ml}$. The ethyl acetate fraction also exhibited significant antioxidant activity. Some studies have reported that plant extracts with antioxidant activity exhibit antiproliferative activity on some cancer cell lines, including the A549 human lung adenoma and MCF-7 human breast cancer cells [15], Caco-2 cells (16) and the Human HeLa cervical cancer cells [15].

This is the first report showing that Cyphostemma adenocaule root extract has cytotoxic activity against a cancer cell line, but other species of Cyphostemma are reported in the literature to have cytotoxic activity against cancer cell lines [17-20]. The essential oil of Cyphostemma juttae was 
reported to exhibit cytotoxic activity against triple negative breast cancer cells and induced apoptosis against acute myeloid leukemia cells [17]. On the other hand, C. serpens, is used alone or in combination with other plants, in traditional medicine for the management of breast cancer [18]. Root extracts of C. vogelii are reported to have anti-inflammatory effect on sore throat, cough and pneumonia in mice [17], which effect may be additive to the cytotoxic activity of its extracts. Four Cyphostemma species; C. flaviflorums, C. lanigerum, C. natalitium, and one unidentified species, are reported to have cytotoxic activity against the HepG2 cell line [19], but there were no isolated chemical compounds. In another study $C$. greveana exhibited antiproliferative activity against the A2780 ovarian cancer cell line and one macrolide, lasiodiplodin, three sesquiterpenoids, and a new diterpenoid were isolated [20]

Evaluation of the overall scenario of the results suggests that extracts of $C$. adenocaule and, indeed, other plants of the genus Cyphostemma have potential to yield useful anticancer compounds and therefore more studies following bioassay-guided isolation to identify active anticancer compounds.

\section{CONCLUSION}

The ethyl acetate extracts of Cyphostemma adenocaule exhibited cytotoxic activity against the HeLa cervical cancer cells in support of claims by traditional health practitioners that the plant may have potential to yield active anticancer compounds. The claims are further supported by the brine shrimp lethality and antioxidant activity results, thus indicating the need for further studies to isolate active compounds.

\section{ETHICAL APPROVAL}

This study was granted Ethical Clearance by the Muhimbili University of Health and Allied Sciences Institutional Ethical Review Board, and given Ref. No. MU 029024 VOL.II, dated 17 October 2015.

\section{FUNDING}

The study was sponsored by the Government Chemist Laboratory Authority (GCLA) - Tanzania and African Laser Centre (ALC) of South Africa and Research Grant Funding of the Nelson Mandela University-South Africa/ NIMR - Tanzania.

\section{Authors`CONTRIBUTIONS}

DZM, FM, ODN and MJM conceived and designed the study. DZM collected plant materials, performed extraction, BST assay of extracts and isolation of compounds. DZM, BS and KO performed bioassay experiments in testing for antioxidant activity and toxicity to HeLa cancer cells. DZM, FM, ODN, MJM, SM, MvdV, LV, TK, BS and KO collectively prepared the manuscript. FM, ODN, MJM, MvdV, LV and SM supervised the study and revised the manuscript. All authors approved the final version of the manuscript.

\section{ACKNOWLEDGEMENT}

I am grateful to my sponsors: The Government Chemist Laboratory Authority (GCLA)-Tanzania and the CSIR/African Laser Centre (ALC) Research Grant Funding of the Nelson Mandela UniversitySouth Africa/ NIMR - Tanzania.

I also appreciate contribution of Mr. Frank Mbago and Selemani Haji, both from Botany Department of Univerity of Dar es salaam for the specie identification and preparation of voucher specimens. Much thanks to Dickson Chikira, Chahe Mavura and Nikombolwe Kibalanga for their response to interviews and participation in sample collection. Finally, I am thankful for moral and technical support from students and staff of the Institute of Traditional Medicine (MUHAS), (GCLA)Tanzania and the Department of Biochemistry and Biology (NMU) - South Africa

\section{REFERENCES}

[1] World Health Organization.,WHO report on cancer: setting priorities, investing wisely and providing care for all,WHO, Geneva. (2020)

[2] Jemal A., Siegel R., Xu J., Ward E., Cancer Statistics , CA cancer J Clin. 60(5),277-300 (2010)

[3] Bello OM., Jagaba SM., Bello OE., Ogbesejana AB., Dada OA., Adetunji CO., Abubakar SM., Phytochemistry, pharmacology and perceived health uses of non-cultivated vegetable Cyphostemma adenocaule (Steud. ex A. Rich.)Desc. ex Wild and R.B. Drumm, A review. Sci African. 2,53, 2019; 
Evaluation of Root Extract of Cyphostemma Adenocaule (Vitaceae) for Antioxidant Activity, Brine Shrimp Toxicity, and Antiproliferative Activity against Hela Cervical Cancer Cells

[4] Teklay A., Abera B., Giday M., An ethnobotanical study of medicinal plants used in Kilte Awulaelo District , Tigray Region of Ethiopia., J Ethnobiol Ethnomed. 9(65), (2013)

[5] Abebe D., Periasamy G., Karim A., Bitew H., Evaluation of the Effect of Hydroethanolic Root Extract and Solvent Fractions of Cyphostemma adenocaule (Steud. ex A. Rich) Descoings ex Wild \& Drummond on Cell-Mediated Immune Response and Blood Cell Count in Mice, Evidence-based Complement Altern Med. 2021,(2021).

[6] Fratkin E., TRADITIONAL MEDICINE AND CONCEPTS OF HEALING AMONG SAMBURU PASTORALISTS OF KENYA, J Ethnopharmacol. 16(1), 63-97 (1996)

[7] Bussa NF., Belayneh A., Traditional medicinal plants used to treat cancer , tumors and in flammatory ailments in Harari Region, Eastern Ethiopia, South African J Bot..122:360-8. (2019)

[8] Hedberg I., Hedberg O., Madat PJ., Mshigeni KE., Mshiu EN., Samuelsson G.. Inventory of plants used in traditional medicine in Tanzania. II1983;. Plants of the families dilleniaceae-Opiliaceae, J Ethnopharmacol. 9(1),105-27, (1983).

[9] Meyer BN., Ferrigni NR., Putnam JE., Jacobsen LB., Nichols DE., McLaughlin JL., Brine shrimp: A convenient general bioassay for active plant constituents., Planta Med.,45(1),31-4 (1982)

[10] Moshi MJ., Innocent E., Otieno JN., Magadula JJ., Nondo RSO., Otieno DF., Wensheit A., Mbabazi P., Antimicrobial and brine shrimp activity of Acanthus pubescens root extracts, Tanzan J Health Res. 12(2) (2010)

[11] Moshi MJ., van den Beukel CJP., Hamza OJM., Mbwambo ZH., Nondo ROS., Masimba PJ., Brine shrimp toxicity evaluation of some Tanzanian plants used traditionally for the treatment of fungal infections, African J Tradit Complement Altern Med. 4(2),(2007);

[12] Benzie IFF., Strain JJ., Ferric reducing (antioxidant) power as a measure of antioxidant capacity: the FRAP assay. Methods Enzym. 1999;299:15-36.

[13] Sandhya Kumari TD., Sudha Madhuri TD., Singara Charya MA., Subba Rao K., Antioxidant and anticancer activities of Nyctanthes arbor-tristis, Int J Pharm Pharm Sci. 4(4),452-4 (2012)

[14] Matata DZ., Moshi MJ., Machumi F., Ngassapa OD., Swanepoel B., Oosthuizen K., Swanepoel B.,Venables L., Koekemoer TC., Paul Erasto Kazyoba PE., van de Venter M., Isolation of a new cytotoxic compound, 3-((Z)-heptadec-14-enyl) benzene - 1-ol from Rhus natalensis root extract, Phytochem Lett. 36(August 2019),120-6 (2020).

[15]Li W., Chan S., Guo D., Yu PH., Li W., Chan S., Correlation Between Antioxidative Power and Anticancer Activity in Herbs from Traditional Chinese Medicine Formulae with Anticancer Therapeutic Effect. 45(October),541-6 (2008).

[16] Ho IYM., Abdul Aziz A., Mat Junit S., Evaluation of Anti-proliferative Effects of Barringtonia racemosa and Gallic Acid on Caco-2 Cells, Sci Rep.10(1),1-13 (2020).

[17]Zito P., Labbozzetta M., Notarbartolo M., Sajeva Id M., Poma P., Essential oil of Cyphostemma juttae (Vitaceae): Chemical composition and antitumor mechanism in triple negative breast cancer cells, Plos one.14(3),e0214594 (2019)

[18] Tesfaye S., Belete A., Engidawork E., Gedif T., Asres K., Ethnobotanical Study of Medicinal Plants Used by Traditional Healers to Treat Cancer-Like Symptoms in Eleven Districts, Ethiopia, Evidence-based Complement Altern Med. 2020, (2020).

[19] Opoku AR., Geheeb-Keller M., Lin J., Terblanche SE., Hutchings A., Chuturgoon A.,Pillay D., Preliminary screening of some traditional Zulu medicinal plants for antineoplastic activities versus the HepG2 cell line, Phytotherapy Research: An International Journal Devoted to Pharmacological and Toxicological Evaluation of Natural Product Derivatives.;14(7), 534-7, (2000)

[20] Cao S., Hou Y., Brodie P., Miller JS., Randrianaivo R., Rakotobe E. Rasamison VE, Kingston DG., Antiproliferative compounds of cyphostemma greveana from a Madagascar dry forest, Chem Biodivers. 8(4),643-50, 2011;

Citation: Daniel Zacharia Matata, et.al., (2021). "Evaluation of Root Extract of Cyphostemma Adenocaule (Vitaceae) for Antioxidant Activity, Brine Shrimp Toxicity, and Antiproliferative Activity against Hela Cervical Cancer Cells". International Journal of Medicinal Plants and Natural Products (IJMPNP), 7(1), pp.19-27. https://doi.org/ 10.20431 /2454-7999.0701003

Copyright: () 2021 Authors. This is an open-access article distributed under the terms of the Creative Commons Attribution License, which permits unrestricted use, distribution, and reproduction in any medium, provided the original author and source are credited. 